\title{
Is langdurig ziekteverzuim voorspelbaar en meetbaar?
}

\author{
K. Goorts ${ }^{1}$, C. Duchesnes ${ }^{3}$, S. Vandenbroeck ${ }^{1,2}$, D. Rusu ${ }^{3}$, M. Du Bois ${ }^{1}, \mathrm{Ph}$. \\ Mairiaux $^{3}$, L. Godderis ${ }^{1,2}$.
}

1 Katholieke Universiteit Leuven, Centre for Environment and Health, Kapucijnenvoer 35/5, 3000 Leuven, Belgium.

2 Idewe, External Service for Prevention and Protection at Work, Interleuvenlaan 58, 3001 Heverlee, Belgium.

3 Universiteit Luik, Médecine du Travail et environnementale, Département des

Sciences de la Santé publique, Belgium

Contact:

KULeuven

Prof. dr. Lode Godderis

Centre for Environment \& Health

Kapucijnenvoer 35/5, 3000 Leuven

Belgium

T: +32-16-373291

F: +32-16-336997

Lode.godderis@kuleuven.be

\section{Inleiding \\ Langdurig verzuim blijft toenemen en zieke werknemers worden onvoldoende ondersteund bij hun terugkeer!}

Recente cijfers van het RIZIV, het beheersorgaan van de ziekteverzekering, tonen aan dat het aantal invalide werknemers (meer dan 1 jaar arbeidsongeschikt omwille van ziekte) in 5 jaar met bijna $25 \%$ is gestegen. De vergrijzing en de vervrouwelijking van de beroepsbevolking verklaren deels de toename van het langdurig ziekteverzuim en arbeidsongeschiktheid in België (1). Het gaat hier vooral over kankers, hart- en bloedvat, mentale en musculoskeletale aandoeningen. De laatste twee aandoeningen zijn de belangrijkste oorzaken van langdurige ziekteverzuim en invaliditeit. (2) Ook ziekteverzuim langer dan een maand en minder dan één jaar blijft toenemen. Dat blijkt uit een analyse van personeelsgegevens van bijna 18000 Belgische ondernemingen: het gemiddeld aantal dagen ziekte langer dan één maand ten opzichte van het aantal dagen dat iemand zou moeten werken steeg van 1,75\% in 2008 naar $2,81 \%$ in 2015 . (3)

Deze stijging, voornamelijk van het langdurig ziekteverzuim, weegt zwaar op het budget van het RIZIV. Een toenemende aandacht voor initiatieven rond de reintegratie van langdurig arbeidsongeschikte werknemers heeft dan ook geleid tot nieuwe wetgeving. Vanaf 1 januari 2016 trad een nieuwe regelgeving in voege waarbij de behandelende arts op het getuigschrift dient te vermelden wat de vermoedelijke einddatum is van de ongeschiktheid. De doelstelling was om het gesprek over re-integratiemoeilijkheden en -mogelijkheden op gang te brengen bij het uitschrijven van het attest. Vanaf 1 januari 2017 wordt deze wetgeving nog aangevuld door 2 KB's over re-integratie. Beide KB's willen de re- 
integratiemogelijkheden bevorderen en te ondersteunen door het kader en takenpakket van zowel de adviserend geneesheer van het ziekenfonds als bedrijfsarts duidelijker te omschrijven. Beide artsen spelen een belangrijke rol in het opvolgen en het begeleiden van de zieke patiënt in zijn re-integratietraject.

Gezien de kans om opnieuw aan de slag te gaan afneemt met de duur van de ongeschiktheid, hebben de meerderheid van werknemers die langer dan 3 maanden afwezig zijn ondersteuning nodig om te kunnen re-integreren. Ze ondervinden vaak moeilijkheden bij de terugkeer naar het werk niet alleen door de aandoening, maar ook door een toenemende onzekerheid en angst voor de terugkeer bij zowel werknemer als werkgever. De nieuwe regelgeving moet deze onzekerheid verminderen. $80 \%$ van de werknemers die langer dan zes weken afwezig zijn, vraagt ook een ondersteuning bij de terugkeer naar werk. Dit kan gaan van het medisch geruststellen, of het aanpakken van angstproblemen tot het vroegtijdig mobiliseren ondanks de pijn zoals bij musculoskeletale aandoeningen.

Deze ondersteuning kan best worden opgestart tussen maand één en maand drie van afwezigheid, om dus snel te beantwoorden aan de ondersteuningsbehoefte en de evolutie naar de chronische fase te vermijden.

Patiënten beter en intensiever ondersteunen kan de sleutel zijn tot een duurzamere en snellere werkhervatting. (4) Gezien de meeste patiënten spontaan hun werk hervatten, zonder dat hierbij begeleiding nodig is, is het belangrijk om de kans op chronisch ziekteverzuim en ondersteuningsbehoeftes proberen in te schatten zodat de inspanningen zich toespitsen op de doelgroep die de grootste nood en risico heeft op langdurig verzuim.

In dit artikel geven we een overzicht van de voorspellende factoren voor een succesvolle terugkeer naar het werk en een overzicht van vragenlijsten die in dit verband kunnen gebruikt worden. Het is vooral belangrijk om in te zetten op modificeerbare risicofactoren, die, in tegenstelling tot de risicofactoren als geslacht en leeftijd, beïnvloedbaar zijn. Deze risicofactoren moeten dan ook het aangrijpingspunt vormen voor preventieve én curatieve acties. Belangrijk is snel te interveniëren gezien de kans op langdurig verzuim na 6 maand zeer hoog is en dus een meetinstrument geen bijkomende toegevoegde waarde biedt. Bovendien zijn ondersteunende maatregelen minder effectief na deze periode. In het kader van de nieuwe wetgeving kunnen deze voorspellende factoren de bedrijfsarts en de arts van het ziekenfonds helpen om hun patiënten beter te begeleiden.

Hoewel het hier een Belgisch onderzoek betreft, kunnen de resultaten ook internationaal van belang zijn. In Nederland is zo sinds 1 januari 2015 de 'participatiewet' in voege. De wet moet ondersteuning bieden voor zieke werknemers die willen re-integreren op de arbeidsmarkt. In tegenstelling tot België, ligt de uitvoering van de wet in Nederland grotendeels bij de gemeenten (29). 


\section{Methode}

De zoektocht naar de factoren die chronisch verzuim voorspellen en instrumenten voor succesvolle hervatting.

Onze zoektocht werd aangevat vanuit twee wetenschappelijke invalshoeken. In eerste instantie hebben we literatuurstudies opgezocht over de factoren die langdurig ziekteverzuim voorspellen. Een overzicht van de volledige zoekstrategie en analysestrategie kan je lezen in het onderzoeksrapport. (5) Vervolgens werd in een bijkomend onderzoek via een sneeuwbaltechniek gezocht naar bestaande, gevalideerde instrumenten die succesvolle werkhervatting voorspellen of meten. Hierbij werd vertrekkend vanuit bestaande vragenlijsten en grijze literatuur, gezocht naar referenties en gelijkaardige artikels in Pubmed op gelijkaardige vragenlijsten, die dan op hun beurt dezelfde procedure ondergaan. Op die manier werd de literatuur systematisch gescreend op vragenlijsten die return to work voorspellen. Finaal werden de resultaten van de literatuurstudie en van de instrumentenanalyse met elkaar vergeleken. Door de combinatie van beide invalshoeken was het mogelijk om de belangrijkste voorspellers en vragenlijsten te identificeren.

\section{Resultaten}

\section{De voorspellers voor chronisch ziekteverzuim}

In totaal leverde de zoektocht 16 voorspellers op. De sneeuwbaltechniek bracht, naast de 8 voorspellers die naar voor kwamen uit de literatuurstudies, nog 8 nieuwe voorspellers naar voor.

\begin{tabular}{|c|c|}
\hline Predictoren & Categorie \\
\hline Leeftijd & \multirow[t]{3}{*}{ Persoonskenmerken } \\
\hline Geslacht & \\
\hline Opleidingsniveau & \\
\hline Perceptie gezondheidstoestand & \multirow[t]{3}{*}{ Perceptie } \\
\hline Eigen voorspelling & \\
\hline Pijn & \\
\hline Klachteninterferentie & Invloed \\
\hline Psychische klachten (distress) & \multirow[t]{4}{*}{ Persoonlijke kenmerken } \\
\hline Perfectionisme/ijverigheid & \\
\hline Vermijding/onzekerheid & \\
\hline Belastende thuissituatie & \\
\hline
\end{tabular}




\begin{tabular}{|l|l|}
\hline Fysiek zware arbeid & \multirow{2}{*}{ Kenmerken arbeidssituatie } \\
\hline Werkdruk & \\
\hline Regelmogelijkheden & \\
\hline Werkbaarheid & \\
\hline Arbeidstevredenheid & \\
\hline
\end{tabular}

De positieve verwachtingen en het gevoel van zelfeffectiviteit ten aanzien van de terugkeer naar het werk zijn de twee duidelijkste positieve voorspellers. (9) De verwachtingen van de patiënt kunnen volgens Shaw het beste bevraagd worden door middel van één vraag:

"Denk je dat je in staat zal zijn om binnen 4 weken je normale werk te hervatten zonder beperkingen?". Deze vraag wordt beantwoord aan de hand van een 5-punt Likert schaal. $(10,11)$

"Zelfeffectiviteit" of "vertrouwen in zijn of haar kunnen om opnieuw aan de slag te gaan" kan gemeten worden met de "return-to-work self-efficacy questionnaire (RTWSE-19)". Een voorbeeldvraag is "hoeveel vertrouwen heb je erin dat je de meeste van je dagdagelijkse activiteiten op het werk kan uitvoeren?" (17). Er bestaat ook een gevalideerde korte 10 -item variant, de RTWSE-10. Deze schaal bepaalt het vertrouwen van de werknemer om hulp te zoeken bij de werkgever en collega's en het vertrouwen om te kunnen omgaan met pijn in de werkcontext. Een voorbeeldvraag uit deze schaal is " $k$ ben in staat om te praten met mijn leidinggevende in geval van problemen tijdens de terugkeer naar het werk" (18). Elke vraag wordt gescoord d.m.v. een 5-punt Likert schaal.

Voor de andere 15 factoren is er meer onzekerheid en is de heterogeniteit in resultaten vrij groot. Van 15 zijn arbeidstevredenheid en opleidingsniveau, regelmogelijkheden en werkbaarheid gunstig voor de terugkeer naar het werk. Negen factoren zijn negatief geassocieerd met re-integratie: leeftijd, het vrouwelijke geslacht, een perceptie van een slechte gezondheidstoestand, de aanwezigheid van pijn, fysiek zware arbeid, klachteninterferentie, vermijding/onzekerheid, hoge werkdruk, een belastende thuissituatie.

Voor het meten van de perceptie op de eigen gezondheidstoestand zijn er verschillende schalen. De "Health Assessment Questionnaire (HAQ)" is een generiek, niet ziekte specifiek instrument dat het niveau van iemands functionele status bepaalt. (6) De "General Health Questionnaire (GHQ)" geeft inzicht in iemands psychische klachten, zoals slapeloosheid, angstklachten, sociaal disfunctioneren en depressie. Er zijn drie versies ter beschikking: de GHQ-12, de GHQ-28 en de GHQ-30, respectievelijk bestaande uit 12, 28 en 30 items. De GHQ 
kan voor twee doeleinden worden gebruikt, namelijk om het niveau van psychische klachten te meten of als screeningsinstrument om mensen met een milde psychisch aandoening (met name angst en depressie) te identificeren. (7) De "Short Form-36 (SF-36) is wereldwijd één van de meest gehanteerde generieke, dus niet ziektespecifiek, meetinstrument om gezondheid gerelateerde kwaliteit van leven in kaart te brengen. De SF-36 bevat 8 sub-schalen, meer specifiek over fysiek functioneren, rolbeperkingen door fysieke problemen, pijn, percepties over de algemene gezondheid, vitaliteit, sociaal functioneren, rolbeperkingen door emotionele problemen en mentale gezondheid. Er zijn twee samenvattende scores, waarvan één over de fysieke component en één over de mentale component. (8)

De variabele pijn kan worden gemeten aan de hand van een visuele analoge schaal (VAS). De visueel analoge schaal is een aspecifieke meetschaal, bestaande uit een horizontale of een verticale lijn. Ook Von Korff (1992) ontwikkelde een vragenlijst om de ernst van chronische pijnen de impact daarvan op persoonlijke activiteiten in kaart te brengen. (13)

Er bestaan verschillende schalen om de fysieke zwaarte van een job in kaart te brengen. Belangrijk is hier om een fysiek zware job te definiëren. Dit kan bijvoorbeeld in termen van heffen en tillen van lasten, werktempo of hoeveelheid werk. Dit is echter niet duidelijk gedefinieerd in de literatuur. $(14,15)$ De vragenlijst voor de Beleving en de Beoordeling van de Arbeid (VBBA) peilt naar de fysieke omstandigheden waarin het werk wordt uitgevoerd. Het gaat hier vooral om de lichamelijke, geestelijke en emotionele belasting die het werk met zich meebrengt. (16)

Belastende thuissituatie wordt gemeten in vier belangrijke vragenlijsten die peilen naar opportuniteiten om terugkeer naar werk mogelijk te maken, namelijk de 'obstacles to return to work questionnaire' (ORO) (27), de 'ROSES (26) (Return to work and self efficacy scale') questionnaire, de Work and Health Questionnaire (WHQ) (21), onder de term 'non-work satisfaction' en de vragenlijst arbeidsreïntegratie (VAR) (22). De vragen gaan na in hoeverre de patiënt al dan niet op steun kan rekenen in zijn/haar omgeving en in hoeverre eventuele thuisproblematieken mee aan de basis kunnen liggen van drempels om terugkeer naar werk mogelijk te maken.

Vermijding onzekerheid is een predictor die werd gemeten in de vragenlijsten 'ROSES' (26), 'VAR' (22), 'ORO' (27), en 'Absenteeism Screening Questionnaire (ASQ) (23). De vragen pijlen naar de mate waarin de patiënt een terugkeer naar werk gaat vermijden uit angst voor een terugval, pijn, nieuwe symptomen, ... en in hoeverre deze onzekerheid karaktergebonden is.

Perfectionisme/ijverigheid werd enkel gemeten in de vragenlijst arbeidsre-integratie (VAR) (22). Prestatiegerichte, perfectionistische mensen maken immers meer kans op langdurig ziekteverzuim, omdat ze zichzelf moeilijk kunnen beschermen tegen hun eigen veeleisendheid.

Werkdruk ten slotte werd in zes vragenlijsten ondervraagd. Zowel de vragenlijst arbeidsreintegratie, als de work and health questionnaire, de Return to work self 
efficacy scale (RTWSE-19)(17), de Vragenlijst beleving en beoordeling van de arbeid (VBBA) (16), de ROSES (26) en de Work Ability Index (WAI) (24) peilen naar deze predictor. Een hoge werkdruk bemoeilijkt de terugkeer naar werk omdat mensen bang zijn snel te hervallen of het werk niet langer aan te kunnen vanwege hun aandoening.

\section{Instrumenten die succesvolle RTW voorspellen}

De vragenlijsten en instrumenten die een succesvolle RTW voorspellen bevragen dus dezelfde eindpunten gevonden werd in de literatuurstudie, en legden nog enkele extra voorspellers bloot. De vragenlijsten die geanalyseerd werden zijn;

De ALBPSQ-NL, de Vragenlijst Arbeidsreïntegratie (VAR), de Brief Illness perception Questionnaire, Brief screening questionnaire, de 'Echelle d'evaluation du sentiment d'efficacite personelle', de General Health Questionnaire '(GHQ), de 'Health Assessment Questionnaire', de Obstacles to return to work Questionnaire (ORO), de Absenteism screening questionnaire (ASQ), de RAND-36, de Readiness to Return to Work Scale (RRTWS), de Risk Screening Questionnaire (RSQ), de Return to work Self Efficacy Scale (RTWSE-19), de SF OMSPQ, de Single-item question on workability, de SPOC-NL, de VBBA, de WAI, de WHQ, de disability Risk Questionnaire, de ROSES.

Uit de analyse van de vragenlijsten konden nog acht nieuwe voorspellers worden gedestilleerd. Dit waren klachteninterferentie, psychische klachten (distress), perfectionisme/ijverigheid, vermijding/onzekerheid, een belastende thuissituatie, werkdruk, regelmogelijkheden en werkbaarheid. In welke mate deze voorspellers ook effectief een voorspellende waarde hebben is nog onduidelijk. Echter, omwille van het feit dat deze voorspellers gebruikt worden in gevalideerde vragenlijsten met betrekking tot return-to-work is het belangrijk om deze mee te nemen in het onderzoek, in het kader van volledigheid.

\section{Conclusie}

De kans op chronisch ziekteverzuim en succesvolle werkhervatting hangt af van een combinatie van ziekteperceptie, persoonlijks- en werkkenmerken. Opvallend is dat voor chronisch verzuim de ziekte zelf minder een rol lijkt te spelen. De meeste voorspellers komen terug onafhankelijk van de ziekte en zijn dus niet ziektespecifiek. Dit heeft ook als gevolg dat de organisatie van de sociale zekerheid een belangrijke impact kan hebben op de re-integratiekans en ondersteuningsmogelijkheden. (28)

Over de impact van elke factor is nog verder onderzoek nodig omdat de sterkte van associatie meestal niet eenduidig is beschreven. Voor elk van de geïdentificeerde parameters is een gevalideerd instrument beschikbaar. Maar indien in de praktijk elke predictor zou bevraagd worden, dan hebben we een te lange vragenlijst nodig. Er is dus nood aan een kort instrument dat de belangrijkste items bevraagt.

Gezien de grote meerderheid van zieke werknemers meestal spontaan het werk hervat binnen de maand, adviseren we om dergelijk instrument pas in te zetten na 
zes weken. Het gaat voor deze periode meestal om zelflimiterende aandoeningen zoals bijvoorbeeld infectieziekten zoals verkoudheden, gastro-enteritis en griep. (3)

Op basis van de resultaten van het onderzoek wordt nu een nieuwe vragenlijst ontwikkeld, waarin de 13 voorspellers zullen worden bevraagd. Deze vragenlijst zal vanaf januari 2017 in België worden uitgetest en gevalideerd in een pilootstudie. Drie voorspellers zullen niet worden bevraagd: leeftijd, geslacht en opleidingsniveau. Immers, de antwoorden op deze vragen zijn in alle gevallen reeds gekend door de adviserend geneesheer. Om dubbel werk voor de patiënt te vermijden worden dus enkel nieuwe elementen ondervraagd.

De nadruk van het onderzoek ligt op de ontwikkeling en validatie van een ondersteunend instrument voor een snellere, efficiëntere en betere begeleiding van de patiënt. De pilootstudie zal toelaten om te onderzoeken of het instrument effectief in staat zal zijn om langdurig ziekteverzuim te voorspellen. Het instrument zal in elk geval zieke werknemers en hulpverleners helpen om het gesprek te openen voor een efficiënte, en duurzame manier om opnieuw aan de slag te gaan.

\section{Bedankingen}

Het onderzoeksteam heeft deze studie uitgevoerd met de steun van de Dienst voor uitkeringen van het RIZIV (directeur: Dhr. François Perl) en het Kenniscentrum Arbeidsongeschiktheid (o.I.v. dr. Saskia Decuman) 


\section{Referenties}

(1) RIZIV. (2016). RG invalidité données 2014-FR-NL. Retrieved from http://www.inami.fgov.be/nl/statistieken/uitkeringen/2014/Paginas/statistiekeninvaliditeit.aspx\#Aantal_invaliden

(2) G. Mylle, P. Henckens, C. Verbeek, D. Wijns, S. Bulterys, M. Coene, C. Wuytens, L. Godderis, Kenmerken van het chronisch ziekteverzuim Hoe langer afwezig, hoe moeilijker terug aan het werk. White paper IDEWE en Acerta, 2016, 13pp

(3) SD worx. (2016). Langdurig ziekteverzuim blijft stijgen en bereikt record. Retrieved from http://www.sdworx.be/nl-be/sd-worx-rd/publicaties/persberichten/2016-02-08-langdurig-ziekteverzuim-blijft-stijgen

(4) Du Bois, M., Nemery, B. (sup.) (2014). Causes and prevention of long-term disability due to low back pain. An inquiry from the perspective of insurance medicine., $215 \mathrm{pp}$.

(5) Mairiaux, P., Donneau, A.-F., Duchesnes, C., Vandenbroeck, S, Godderis, L. (2015). Ontwikkeling van een instrument voor identificatie van de personen met een verhoogde kans op een geslaagde sociaalprofessionele re-integratie, Riziv.

(6) Fries JF, Bruce B, Rose M. Comparison of the health assessment questionnaire disability index and the short form 36 physical functioning subscale using Rasch analysis: comment on the article by Taylor and McPherson. Arthritis and rheumatism. 2008;59(4):598-9; author reply 9.

(7) Lesage FK, Martens_resende S, Deschamps F, Berjot S. Validation of the General Health Questionnaire (GHQ-12) adapted to a work-related context. Journal of Preventive Medicine. 2011;1(2):44-8.

(8) Ware JE, Jr., Sherbourne CD. The MOS 36 -item short-form health survey (SF36). I. Conceptual framework and item selection. Medical care. 1992;30(6):473-83.

(9) Bialosky JE, Bishop MD, Cleland JA. Individual expectation: an overlooked, but pertinent, factor in the treatment of individuals experiencing musculoskeletal pain. Physical therapy. 2010;90(9):1345-55.

(10) Young AE, Besen E, Choi Y. The importance, measurement and practical implications of worker's expectations for return to work. Disability and Rehabilitation. 2015;37(20):1808-16.

(11) Shaw WS, Pransky G, Winters T. The Back Disability Risk Questionnaire for work-related, acute back pain: prediction of unresolved problems at 3-month followup. Journal of occupational and environmental medicine / American College of Occupational and Environmental Medicine. 2009;51(2):185-94.

(12) Hjermstad MJ, Fayers PM, Haugen DF, Caraceni A, Hanks GW, Loge JH, et al. Studies comparing Numerical Rating Scales, Verbal Rating Scales, and Visual Analogue Scales for assessment of pain intensity in adults: a systematic literature review. Journal of pain and symptom management. 2011;41(6):1073-93. 
(13) Von Korff M, Ormel J, Keefe FJ, Dworkin SF. Grading the severity of chronic pain. Pain. 1992;50(2):133-49.

(14) Steenstra IA, Verbeek JH, Heymans MW, Bongers PM. Prognostic factors for duration of sick leave in patients sick listed with acute low back pain: a systematic review of the literature. Occupational and environmental medicine. 2005;62(12):85160 .

(15) van Muijen P, Weevers NL, Snels IA, Duijts SF, Bruinvels DJ, Schellart AJ, et al. Predictors of return to work and employment in cancer survivors: a systematic review. European journal of cancer care. 2013;22(2):144-60.

(16) Van Veldhoven M, Meijman TF. Het meten van psychosociale arbeidsbelasting met een vragenlijst: de vragenlijst beleving en beoordeling van de arbeid (VBBA). Amsterdam: NIA; 1994.

(17) Shaw WS, Reme SE, Linton SJ, Huang YH, Pransky G. 3rd place, PREMUS best paper competition: development of the return-to-work self-efficacy (RTWSE-19) questionnaire--psychometric properties and predictive validity. Scandinavian journal of work, environment \& health. 2011;37(2):109-19.

(18) Brouwer S, Franche RL, Hogg-Johnson S, Lee H, Krause N, Shaw WS. Returnto-work self-efficacy: development and validation of a scale in claimants with musculoskeletal disorders. Journal of occupational rehabilitation. 2011;21(2):244-58.

(19) Steijn B. Human resource management and job satisfaction in the Dutch public sector. Review of Public Personnel Administration. 2004;24(4):291-303.

(20) van der Zee, K. I., \& Sanderman, R. (2012). Het meten van de algemene gezondheidstoestand met de Rand-36. Groningen: Research institute SHARE (UMCG)/Rijksuniversiteit Groningen.

(21) Shikiar, R., Halpern, M. T., Rentz, A. M., \& Khan, Z. M. (2004). Development of the Health and Work Questionnaire (HWQ): an instrument for assessing workplace productivity in relation to worker health. Work, 22(3), 219-229.

(22) Vendrig, A. A., et al. "Voorspellen van de verwachte verzuimduur met de Vragenlijst ArbeidsReïntegratie (VAR)." TBV-Tijdschrift voor Bedrijfs-en Verzekeringsgeneeskunde 19.1 (2011): 7-13.

(23) Truchon, M., Schmouth, M.-E., Côté , D., Fillion, L., Rossignol, M., \& Durand, M.-J. (2012). Absenteeism Screening Questionnaire (ASQ): A New Tool for Predicting Long-term Absenteeism Among Workers with Low Back Pain. Journal of occupational rehabilitation , 27-50.

(24) Ahlstrom, L., Grimby-Ekman, A., Hagberg, M., \& Dellve, L. (2010). The work ability index and single-item question: associations with sick leave, symptoms, and health--a prospective study of women on long-term sick leave. Scand J Work Environ Health, 36(5), 404-412.

(25) Corbiere, M., Negrini, A., Durand, M. J., St-Arnaud, L., Briand, C., Fassier, J. B., . . L Lachance, J. P. (2016). Development of the Return-to-Work Obstacles and Self- 
(26) Efficacy Scale (ROSES) and Validation with Workers Suffering from a Common Mental Disorder or Musculoskeletal Disorder. J Occup Rehabil. doi:10.1007/s10926016-9661-2

(27) Marhold, C., Linton, S. J., \& Melin, L. (2002). Identification of obstacles for chronic pain patients to return to work: evaluation of a questionnaire. J Occup Rehabil, 12(2), 65-75.

(28) Anema, J. R., Schellart, A. J., Cassidy, J. D., Loisel, P., Veerman, T. J., \& van der Beek, A. J. (2009). Can cross country differences in return-to-work after chronic occupational back pain be explained? An exploratory analysis on disability policies in a six country cohort study. J Occup Rehabil, 19(4), 419-426. doi:10.1007/s10926009-9202-3

(29) Uitvoeringsinstituut Werknemersverzekeringen. (2016). Participatiewet. Retrieved from http://www.uwv.nl/overuwv/wat-is-uwv/index.aspx 